\title{
Oral Misoprostol 2 Hourly for Labor Induction
}

\author{
Souzan Kafy \\ Department of Obstetrics and Gynecology, King Abdulaziz University, Jeddah, KSA \\ Email: souzankafy@yahoo.ca
}

How to cite this paper: Kafy, S. (2018) Oral Misoprostol 2 Hourly for Labor Induction. Open Journal of Obstetrics and Gynecology, 8, 553-558. https://doi.org/10.4236/ojog.2018.86062

Received: January 28, 2018

Accepted: June 3, 2018

Published: June 6, 2018

Copyright $\odot 2018$ by author and Scientific Research Publishing Inc. This work is licensed under the Creative Commons Attribution International License (CC BY 4.0).

http://creativecommons.org/licenses/by/4.0/

\begin{abstract}
The objective of this study was to assess the efficacy and safety of the 2 hourly oral misoprostol for labor induction. Between May and November 2013, the hospital records of 83 women who were induced for labor and met the eligibility criteria were retrospectively reviewed. Eligibility criteria were singleton pregnancy of at least 34 weeks' gestation and a baseline Bishop score $<6$. Women with a previous cesarean section or other uterine surgery, severe pregnancy-induced hypertension, and parity of 4 or more were excluded. Oral misoprostol was administered as $20 \mu \mathrm{g} 2$ hourly unless active labor. A maximum of 12 doses was allowed. The age of the women was $27.9 \pm 5.3$ years (mean $\pm \mathrm{SD}$ ). Vaginal delivery within 24 hours occurred in 38 (45.8\%) women. Cesarean delivery occurred in 17 (20.5\%) women. Although more parous women achieved vaginal delivery within 24 hours (52.6\%) compared with nulliparous women $(40.0 \%)$, the difference was not significant $(\mathrm{P}=.35)$. Uterine tachysystole occurred in $12(14.5 \%)$ women. No perinatal deaths or neonatal intensive care unit admission occurred in the study group. Evidence supporting an optimal regimen is lacking, and additional research is warranted to optimize the use of oral misoprostol for the induction of labor.
\end{abstract}

\section{Keywords}

Recommended Oral Misoprostol Regimen, Induction of Labor

\section{Introduction}

Labor induction is a common obstetrical intervention. The natural prostaglandin $\mathrm{E}_{2}$ (dinoprostone) and the synthetic prostaglandin $\mathrm{E}_{1}$ analog (misoprostol) are effective pharmacological agents for inducing labor. Dinoprostone is approved by the U.S. Food and Drug Administration (FDA) for cervical ripening in pregnant women at or near term, and it has become the drug of choice in many countries [1]. It is commercially available as a vaginal suppository, vaginal and cervical gel, and vaginal insert. Misoprostol is approved by the FDA for re- 
ducing the risk of non-steroidal anti-inflammatory drugs-induced gastric ulcers. The American College of Obstetricians and Gynecologists (ACOG) recommended misoprostol for cervical ripening for induction of labor and that the dose should be $25 \mu \mathrm{g}$ [2]. The WHO recommended the use of $25 \mu \mathrm{g}$ oral misoprostol 2 hourly or $25 \mu \mathrm{g}$ vaginal misoprostol 6 hourly for labor induction at term [3]. These recommendations are endorsed by International Federation of Gynecology and Obstetrics (FIGO) [4]. A recent Cochrane review of randomized clinical trials (RCTs) concluded that oral misoprostol is as effective as vaginal misoprostol, results in fewer cesarean sections than vaginal dinoprostone, and the dose should be 20 to $25 \mu \mathrm{g}$ of oral misoprostol in solution (OMS) [5]. Misoprostol was manufactured and licensed to be taken orally. Nevertheless, vaginal, sublingual, buccal and rectal routes of administration were used in clinical practice in obstetrics and gynecology. After oral misoprostol administration, uterine tonus develops which is followed by uterine contractions with repeated doses [6]. The time to onset of action is 8 minutes, and the terminal half-life is 20 - 40 minutes. The objective of this study was to assess the efficacy and safety of the recommended 2 hourly misoprostol regimen for labor induction.

\section{Materials and Methods}

After receiving institutional review board approval from the King Abdulaziz University Hospital, the records of women who met the eligibility requirements between May and November 2013, were reviewed. Eligibility criteria included singleton pregnancy of at least 34 weeks' gestation and a baseline Bishop score < 6. Women with a previous cesarean section or other uterine surgery, severe pregnancy-induced hypertension (abnormal liver function tests, protein $>1 \mathrm{~g} / \mathrm{d}$, blood pressure of 160/100 mmHg), parity of 4 or more were excluded. Oral misoprostol solution was administered as $20 \mathrm{~mL}$ from a $1 \mu \mathrm{g} / \mathrm{mL}$ solution prepared by dissolving a $200 \mathrm{mcg}$ misoprostol tablet (Cytotec; Searle Pharmaceuticals, Leicester, UK) in $200 \mathrm{~mL}$ water as described before [7]. Doses were administered 2 hourly unless active labor, with uterine contractions every 3 - 5 minutes lasting 60 seconds or more, was established during the inter-dose interval. A maximum of 12 doses was allowed. If contractions subsequently became inadequate, oxytocin augmentation was provided at least 2 hours after the last misoprostol dose. The primary outcome variable was successful labor induction, defined as the proportion of women achieving vaginal delivery within 24 hours after treatment initiation. Secondary outcomes included the rate of cesarean delivery and need for augmentation with oxytocin. Safety assessments included the incidence of maternal morbidity and adverse neonatal outcomes. Uterine tachysystole was defined as more than five contractions in a 10 minute period without fetal heart rate changes and uterine hyperstimulation as tachysystolic uterine contractions associated with nonreassuring fetal heart rate pattern. Non-reassuring fetal heart rate was defined as an abnormal fetal heart rate on electronic monitoring. The data were analyzed using the Statistical Package for the Social Sciences (SPSS 
Inc., Chicago, IL, USA), version 22.0.

\section{Results}

During the study period, 83 women met the eligibility criteria. The age of the women was $27.9 \pm 5.3$ years (mean $\pm \mathrm{SD}$ ), post-term pregnancy was the indication in 54 (65.1) women, and the Bishop score was $\leq 3$ in 75 (90.4\%) women (Table 1). The median dose of misoprostol was $160 \mu \mathrm{g}$ (range, 20 - 240). Vaginal delivery within 24 hours occurred in 38 (45.8\%) women. Vaginal delivery before 12 hours occurred in $11(13.3 \%)$ women. Cesarean delivery occurred in 17 (20.5\%) women. Although more parous women achieved vaginal delivery within 24 hours (52.6\%) compared with nulliparous women $(40.0 \%)$, the difference was not significant $(\mathrm{P}=0.35)$. Uterine tachysystole occurred in $12(14.5 \%)$ compared to $1(1.2 \%)$ with uterine hyperstimulation (Table 2$)$. No perinatal deaths or neonatal intensive care unit admission occurred in the study (Table 3 ).

Table 1. Baseline characteristics.

\begin{tabular}{cc}
\hline Variable & Misoprostol 2 hourly static dose $(\mathbf{n}=\mathbf{8 3})$ \\
\hline Age, $\mathrm{y}$ & $27.9 \pm 5.3(17-43)$ \\
Gestation, wks & $39.8 \pm 1.4(37-43)$ \\
BMI, $\mathrm{kg} / \mathrm{m}^{2}$ & $32.6 \pm 6.6(19.8-54.6)$ \\
Nulliparous, $\mathrm{n}(\%)$ & $45(54.2)$ \\
Bishop score $\leq 3, \mathrm{n}(\%)$ & $75(90.4 \%)$ \\
Indication, $\mathrm{n}(\%)$ & \\
Post-term & $54(65.1)$ \\
IUGR & $4(4.8)$ \\
PIH & $11(13.3)$ \\
Diabetes & $13(15.7)$ \\
Oligohydramnios & $6(7.2)$ \\
PROM & 0 \\
Other & $7(8.4)$
\end{tabular}

Data are mean \pm SD (range) or number (percentage). BMI, body mass index; IUGR, intrauterine growth restriction; PIH, pregnancy induced hypertension; PROM, premature rupture of membranes.

Table 2. Maternal adverse events.

\begin{tabular}{cc}
\hline Variable & Misoprostol 2 hourly static dose $(\mathbf{n}=\mathbf{8 3})$ \\
\hline Uterine tachysystole & $12(14.5)$ \\
Uterine hyperstimulation & $1(1.2)$ \\
Shivering & $4(4.8)$ \\
Vomiting & $1(1.2)$ \\
Nausea & $1(1.2)$ \\
Pyrexia & $1(1.2)$ \\
\hline
\end{tabular}

Data are number (percentage). 
Table 3. Neonatal outcomes.

\begin{tabular}{cc}
\hline Variable & Misoprostol 2 hourly static dose $(\mathbf{n}=\mathbf{8 3})$ \\
\hline Nonreassuring fetal heart rate & $11(13.3)$ \\
Meconium-stained liquor & $16(19.3)$ \\
Birth weight, g & $3262.8 \pm 453$ \\
Preinatal death & 0 \\
Apgar score $<7$ at 1 min & $7(8.4)$ \\
Apgar score $<7$ at 5 min & 0 \\
NICU admission, n $(\%)$ & 0 \\
\hline
\end{tabular}

NICU, neonatal intensive care unit. Data are mean \pm SD (range) or number (percentage).

\section{Discussion}

Although misoprostol is not approved for labor induction, its low cost, stability at room temperature, multiple administration routes, and greater acceptability among pregnant women with oral administration contributed to its widespread off-label use in Europe and most other countries [8]. Many randomized controlled trials have searched for the optimum induction of labor regimen for successful vaginal delivery with fewer adverse effects. The latest Cochrane Database of Systematic Reviews based on 76 trials (14,412 women), recommended that when using oral misoprostol, the dose should be 20 to $25 \mu \mathrm{g}$ in solution 2 hourly [5].

In the current study, the 83 women treated with $20 \mu \mathrm{g}$ of an oral misoprostol solution 2 hourly had lesser delivery success at 24 hours of $45.8 \%$ compared with $79.7 \%$ with $25 \mu \mathrm{g}$ misoprostol 2 hourly for 12 doses [9]. This subject could be treated a maximum of 12 times with $20 \mu \mathrm{g}$ oral misoprostol solution (maximum possible dose: $250 \mu \mathrm{g}$ ). Earlier studies using this dose and dose interval allowed a maximum of $4(80 \mu \mathrm{g})$ Moodly [10] and $6(120 \mu \mathrm{g})$ Dodd [11] doses, yet reported 24 -hour vaginal delivery rates of $55.3 \%$ and $54.0 \%$, compared with $45.8 \%$ in this cohort. The majority of recent studies examined $50 \mu \mathrm{g}$ oral misoprostol every 4 hours, with success in at least $70 \%$ of women reported from several studies (e.g., Jindal [12], Mehrotra [13], Nagpal [14]). The discrepancy in vaginal delivery rates between these studies and the current study may be related to heterogeneity among studies. For example, eligibility for women in the study by Jindal et al. [12] included ruptured membranes, which have been widely studied in oral misoprostol studies. The Jindal study also required Bishop score $\leq 4$, compared with $\leq 6$ in the study by Rahman et al. [15]. Women in the Nagpal study [12] were given oxytocin if they were not in active labor after the maximum of 3 doses. Almost two-thirds (64.5\%) had delivered during the 12-hour maximally allowed dosing interval, with only $16.1 \%$ requiring oxytocin. Although a total of 5 oral doses of $50 \mu \mathrm{g}$ were possible in the study by Rahman et al. [15], the women received a mean of 2.33 doses. However, the reported mean dose $(163 \mu \mathrm{g})$ was similar to that $(165 \mu \mathrm{g})$ used in the current study, and both 
groups had similar low 24-hour delivery. These variable women characteristics, regimens, and outcomes suggest that the optimal regimen and the population for induction of labor with oral misoprostol are not yet clarified. A more effective regimen with more consistent outcomes is needed. Therefore, the oral route is worthy of continued investigation. Also, the acceptability of introducing a recommended protocol without a parallel comparison group is consistent with any effort to get with the Guidelines. In conclusion, more research is needed to optimize the use of oral misoprostol for the induction of labor.

\section{References}

[1] Weeks, A., Alfirevic, Z., Faúndes, A., Hofmeyr, G.J., Safar, P. and Wing, D. (2007) Misoprostol for Induction of Labor with a Live Fetus. International Journal of $G y$ necology \& Obstetrics, 99, S194-S97.

[2] Induction of Labor (2009) ACOG Practice Bulletin No. 107. American College of Obstetricians and Gynecologists. Obstetrics and Gynecology, 114, 386-397.

[3] Tang, J., Kapp, N., Dragoman, M. and de Souza, J.P. (2013) WHO Recommendations for Misoprostol Use for Obstetric and Gynecologic Indications. International Journal of Gynecology \& Obstetrics, 121, 186-189. https://doi.org/10.1016/j.ijgo.2012.12.009

[4] International Federation of Gynecology and Obstetrics (2016) Misoprostol Recommended Dosages 2012.

http://www.figo.org/sites/default/files/uploads/project-publications/Miso/Misoprost ol_Recommended\%20Dosages\%202012.pdf

[5] Alfirevic, Z., Aflaifel, N. and Weeks, A. (2016) Oral Misoprostol for Induction of Labor.

http://onlinelibrary.wiley.com/doi/10.1002/14651858.CD001338.pub3/abstract;jsessi onid=F951A83000DA2092D50B29EA07ACA8CC.f04t02

[6] Tang, O.S., Gemzell-Danielsson, K. and Ho, P.C. (2007) Misoprostol: Pharmacokinetic Profiles, Effects on the Uterus and Side-Effects. International Journal of $G y$ necology \& Obstetrics, 99, S160-S167.

[7] Safe Usage Guide for Obstetrics and Gynecology. How to Dilute $200 \mathrm{mcg}$ of Misoprostol in $200 \mathrm{ml}$ Water.

http://www.misoprostol.org/dilute-200-mcg-misoprostol-200ml-water/

[8] Voigt, F., Goecke, T.W., Najjari, L., Pecks, U., Maass, N. and Rath, W. (2015) Off-Label Use of Misoprostol for Labor Induction in Germany: A National Survey. European Journal of Obstetrics \& Gynecology and Reproductive Biology, 187, 85-89. https://doi.org/10.1016/j.ejogrb.2014.11.026

[9] Aalami-Harandi, R., Karamali, M. and Moeni, A. (2013) Induction of Labor with Titrated Oral Misoprostol Solution versus Oxytocin in Term Pregnancy: Randomized Controlled Trial. Revista Brasileira de Ginecologia e Obstetrícia, 35, 60-65. https://doi.org/10.1590/S0100-72032013000200004

[10] Moodley, J., Venkatachalam, S. and Songca, P. (2003) Misoprostol for Cervical Ripening at and Near Term-A Comparative Study. SAMJ, 93, 371-374.

[11] Dodd, J.M., Crowther, C.A. and Robinson, J.S. (2006) Oral Misoprostol for Induction of Labor at Term: Randomized Controlled Trial. BMJ, 332, 509-511.

[12] Jindal, P., Avasthi, K. and Kaur, M. (2011) A Comparison of Vaginal vs. Oral Misoprostol for Induction of Labor-Double-Blind Randomized Trial. The Journal of $\mathrm{Ob}$ - 
stetrics and Gynecology of India, 61, 538-542.

https://doi.org/10.1007/s13224-011-0081-0

[13] Mehrotra, S., Singh, U. and Gupta, H.P. (2010) A Prospective Double-Blind Study Using Oral versus Vaginal Misoprostol for Labor Induction. Journal of Obstetrics and Gynaecology, 30, 461-464. https://doi.org/10.3109/01443615.2010.485253

[14] Nagpal, M.B., Raghunandan, C. and Saili, A. (2009) Oral Misoprostol versus Intracervical Prostaglandin E2 Gel for Active Management of Premature Rupture of Membranes at Term. International Journal of Gynecology \& Obstetrics, 106, 23-26. https://doi.org/10.1016/j.ijgo.2009.03.014

[15] Rahman, H., Pradhan, A., Kharka, L., Renjhen, P., Kar, S. and Dutta, S. (2013) Comparative Evaluation of 50 Micrograms Oral Misoprostol and 25 Micrograms Intravaginal Misoprostol for Induction of Labor at term: A Randomized Trial. Journal of Obstetrics and Gynaecology Canada, 35, 408-416.

https://doi.org/10.1016/S1701-2163(15)30931-2 